\title{
NAJAT EL HACHMI - DISCURSO DE RESISTÊNCIA E IDENTIDADE NO CONTEXTO DA MIGRAÇÃO
}

Sabriny S. Santos ${ }^{1}$

Resumo: O presente artigo visa analisar o romance La filla estrangera (2015), de Najat El Hachmi, com o objetivo de verificar como se dá a construção identitária de mulheres migrantes através da narrativa de migração. O estudo ainda procura dar destaque ao discurso de resistência projetado por El Hachmi em sua obra e a reivindicação por uma construção identitária que deixe em evidência a sua própria voz e sua existência enquanto sujeito autônomo. Para tanto, a fundamentação teórica das discussões propostas será baseada na perspectiva Análise do Discurso - Patrick Charaudeau (2009) - sobre os conceitos de identidade social e discursiva. Com a análise, foi possível compreender a obra de El Hachmi como uma importante manifestação de resistência. Ao contestar imaginários sobre a mulher migrante, a autora coloca em evidência a urgência de se tratar da construção de identidades na migração por uma perspectiva mais plural que leve em consideração a voz migrante.

Palavras-chave: Najat El Hachmi; Migração; Análise do Discurso; Escrita feminina; Identidade.

"Migram as mulheres em travessias em que os sonhos e os pesadelos se entrelaçam, em que a vontade de sair se coaduna com o desejo do retorno. A migração, assim, se torna, não raramente, uma experiência de fragmentação,

onde nem sempre o coração acompanha os caminhos dos pés." (Milesi \& Marinucci, 2016)

\section{Introdução}

A temática das migrações permeia o imaginário do universo literário como um ponto importante para entender e desbravar o desconhecido. Seja por uma perspectiva coletiva ou pela narrativa de uma vivência pessoal, o ato de migrar instiga o confronto com a diferença e com as várias possibilidades de percepção do mundo.

\footnotetext{
${ }^{1}$ Doutoranda em línguas Românicas pela Heinrich-Heine-Universität Düsseldorf/Alemanha (HHU). Mestre em Estudos Linguísticos - Linguística do Texto e do Discurso pela Universidade Federal de Minas Gerais (UFMG). E-mail: sados100@uni-duesseldorf.de
} 
A partir dos anos de 1980, observa-se um crescente número de obras literárias que procuram refletir sobre a experiência migratória e trazer uma perspectiva que coloque à tona não apenas aspectos econômicos e sociais desse fenômeno, mas a problematização de questões como as relações de gênero, raça e crenças religiosas, as quais interpelam a vida de muitos migrantes. Essa mudança na composição das obras correlaciona-se com a recomposição dos movimentos de migração, iniciados no final do século $\mathrm{XX}^{2}$, e com a tomada de voz de sujeitos migrantes que passam a escrever e reivindicar a própria história. Segundo Paterson (2015, p.181), os textos produzidos nesse contexto "não apenas renovaram a instituição literária, mas também modificaram a representação do sujeito na escrita, nela inscrevendo a voz de estrangeiros, de exilados, ou seja, de pessoas que se percebem como "Outro no país de acolhida".

Dentre esses novos protagonistas e autores de histórias sobre a migração, destaca-se a presença de mulheres escritoras, ${ }^{3}$ que carregam, para além da marca do "Outro" /migrante, a condição de gênero socialmente não reconhecido como alteridade positiva, com características próprias e independentes das imposições masculinas (BEAUVOIR, 1970). O “Outro" feminino, que quase sempre permeia o imaginário da não existência enquanto sujeito capaz de estabelecer suas próprias identidades, realidades e narrativas, encontra no discurso literário e na escrita uma maneira de resistir às amarras sociais e culturais, uma passagem do ser "objeto" - que tem sua realidade definida por outros - ao ser "sujeito" autônomo capaz de refletir e construir sua própria realidade (HOOKS, 1989, p. 42).

Observando a complexidade do tema migração e gênero e a tomada de voz de escritoras migrantes na contemporaneidade, propõe-se, neste artigo, a análise do romance da escritora catalã de origem marroquina Najat El Hachmi, La filla estrangera (2015).

Antes de adentrarmos nas entrelinhas do romance, é importante realizar um pequeno adendo em relação à importância da língua na obra da autora catalã/ marroquina. Najta El Hachmi possui uma identidade linguística complexa, sua história está entrelaçada por várias línguas e culturas, entre elas o amazigh/rifenho (língua berberese) $)^{5}$, o catalão e o castelhano. A relação da autora com essas línguas é marcada não apenas em sua biografia (pelo contexto de migração), mas também em sua produção literária como parte importante de sua identidade criativa. A língua catalã, nesse cenário, é eleita como língua principal para a manifestação de seus pensamentos e a criação literária. Segundo Miriam Abdeselam Canales

\footnotetext{
${ }^{2} \mathrm{~A}$ mudança composicional destacada aqui refere-se às correntes migratórias de indivíduos oriundos de países considerados de "terceiro mundo" para países europeus e/ou de economias mais estáveis, almejando novos contornos sociais e financeiros. (Campos \& Rodrigues, 2006)

${ }^{3}$ A título de exemplo, podemos citar as escritoras Chimamanda Ngozi Adiche, Llila Slimani, Najat El Hachmi, Paloma Vidal e Sheena Kamal e Yaa Giasi como representantes desse movimento de migrantes autoras.

${ }^{4}$ Na tradução castelhana de Rosa María Prats: La hija estrangera (2015).

${ }^{5}$ No uso corrente, a cultura berbere refere-se ao conjunto de povos do Norte da África que falam línguas berberes, da família de línguas afro-asiáticas, como o amazight tarifit (ou rifenho) falado povo berbere zeneta que habitam as montanhas do Rife oriental, no nordeste do Marrocos.
} 
(2016, p.25), em um artigo sobre a identidade linguística de Najat El Hachmi, a escolha do catalão como veículo de expressão é fruto do impacto da sua integração na Catalunha, região de destino de muito migrantes rifenhos (as) nos anos 70. Uma integração muitas vezes marcada pela aculturação e pela adoção da língua dominante, em detrimento de outra língua minoritária, no caso de El Hachmi o catalão em detrimento do amazigh ${ }^{65}$ Porém, esse histórico não parece ser linear na trajetória da autora, pois esta mantém em sua obra um discurso de afirmação no que diz respeito ao bilinguismo/plurilinguismo, sem deixar de levantar questionamentos, reflexões, e discussões sobre a integração de migrantes e a complexa relação entre língua, cultura e discriminação. Em sua obra de estreia $J o$ també sóc catalana (2004) ${ }^{7}$, por exemplo, a autora expõe sua visão sobre a relação com a alteridade, como falante do amazigh e do catalão. Por um lado, El Hachmi explora a importância de manter sua língua natal, como forma de resistência e afirmação da história de um povo; por outro mostra-se consciente da importância do conhecimento da língua do país de acolhida: aprender o catalão era uma "necessidade vital” (EL HACHMI, 2004, p.38). A escritora transita por várias línguas e mesmo elegendo o catalão como sua língua do pensamento, não deixa de tratar da identidade linguística em suas obras, como será tratado, posteriormente, na análise do romance La filla estrangera (2015).

A análise terá como foco os recursos discursivos utilizados por El Hachmi para construir a(s) identidade(s) da personagem principal do romance e o jogo de imaginários ${ }^{8}$ sobre a mulher migrante de origem muçulmana em uma país de cultura ocidental. Para a consecução desse objetivo, será utilizada como base para a análise do romance a Análise do Discurso (doravante $\mathrm{AD}$ ) com as teorizações de Patrick Charaudeau (2009) sobre os conceitos de identidade social e discursiva.

\section{0 romance e a construção identitária}

La filla estrangera (2015) conta a história de uma jovem marroquina que migrou com a mãe para o interior da Catalunha em busca do pai que as abandonou. $\mathrm{O}$ nome da personagem principal do romance não é revelado em nenhum momento da história, fato que não interfere no processo narrativo, mas que demonstra a intenção da autora de realizar um movimento que vai do íntimo ao coletivo. A

\footnotetext{
${ }^{6}$ Para aprofundar na temática língua e identidade na obra e vida de Najat El Hachmi, indicamos os seguintes artigos, a saber: CANALES, Miriam Abselam. La identidad compleja de Najat El Hachmi Buhhu. In: Ambigua, Revista de Investigaciones sobre Género y Estudios Culturales. Sevilla: n.3, 2016. p. 23-38 Disponível em: <<: https://www.upo.es/revistas/index.php/ambigua/article/view/1971 > e Gonçalves, A. B. R. (2012). Habitar várias línguas: a escrita multiterritorializada de Najat el Hachmi. Gragoatá, 17(33). Disponível em: <<https:// doi.org/10.22409/gragoata.v17i33.33014 >> Acesso em: 24 de junho de 2021.

${ }^{7}$ Na tradução castelhana Yo también soy catalana (2004).

${ }^{8}$ Os imaginários ou imaginários sociodiscursivos podem ser compreendidos dentro da Análise do Discurso (Teoria Semiolinguística) como o resultado de uma atividade de representação que constrói universos de pensamento, lugares de instituição de verdades, e essa construção se faz pelo viés da sedimentação de discursos narrativos e argumentativos, propondo uma explicação dos fenômenos do mundo e dos comportamentos humanos. (CHARAUDEAU, 2007)
} 
jovem projetada por Najat El Hachmi, desse modo, poderia representar o reflexo de sua própria face ou de qualquer outra mulher em um contexto semelhante.

No plano da enunciação, há a prevalência do "eu" e a rejeição de vozes externas. A personagem principal ou o sujeito psicossocial ${ }^{9}$ que fala assume a postura daquele que escreve e produz um discurso sobre si e sobre os outros. O discurso construído no plano da enunciação possui grande relevância, visto que será justamente a partir dos atos discursivos difundidos socialmente que as identidades serão construídas (CHARAUDEAU, 2009). Essa construção identitária é baseada em dois tipos de identidades, a saber: Identidade social - que envolve o componente biológico e o psicossocial e a Identidade discursiva - que envolve o componente "comportamental" de linguagem.

A identidade social para Patrick Charaudeau (2009) possui como característica a necessidade de ser reconhecida pelos outros, uma vez que ela é responsável por instalar a legitimidade do falante - o seu direito à fala. A conquista da legitimidade é o que determina como os indivíduos poderão agir em contextos específicos. Porém, como essa legitimidade é conquistada? Quais ações legitimam o sujeito a falar sobre determinado assunto?

Segundo o linguista, a legitimidade pode ser atribuída ou reconhecida através de certas habilidades ou características que o indivíduo possui, a saber: ser portador de um determinado saber que seja reconhecido institucionalmente ou de um saber-fazer reconhecido pela performance desse indivíduo; ocupar uma determinada posição de poder reconhecida, filiação ou eleição por condecoração; estar em posição de testemunha do vivido ou por seu engajamento pessoal, o que lhe confere autoridade para falar de determinado acontecimento; ter valor reconhecido pelos membros de um determinado grupo ou comunidade (CHARAUDEAU, 2009).É importante lembrar que a identidade social não é estável. Ela pode sofrer mudanças, ser reivindicada, negociada e deslocada. Além disso, a legitimidade que resulta na identidade social não ocorre de forma homogênea na sociedade. Portanto, para delimitar a identidade social do sujeito, deve-se considerar, para além do contexto de fala, as relações de poder, de raça e de gênero envolvidas na comunicação. Por exemplo, no caso de migrantes vindos de comunidades socialmente marginalizadas, é possível que a identidade social desses sujeitos não seja reconhecida por todos os agentes sociais ou apenas por determinados grupos, apesar de muitos deles serem assegurados pelas habilidades de legitimação citadas anteriormente.

Apesar do livro La filla estrangera (2015) não ser um romance autobiográfico, muitos temas tratados vão ao encontro da história de vida da autora, ou seja, sua identidade social. Por isso, com a intenção de aprofundar a análise das identidades construídas ao longo da narrativa, serão abordadas, resumidamente, as habilidades

\footnotetext{
${ }^{9} \mathrm{O}$ termo psicossocial refere-se à relação entre o convívio social do ponto de vista da psicologia. Consiste, desse modo, em um ramo de estudo que abarca os aspectos da vida social em conjunto com aspectos psicológicos dos sujeitos.
} 
e ações que legitimam a identidade social da escritora Najat El Hachmi, enquanto uma importante voz para tratar a questão da migração na contemporaneidade.

\section{Identidade social: A voz de resistência de Najat El Hachmi}

Najat El Hachmi nasceu em Beni Sidel, Marrocos (1979), e aos oito anos migrou com a família para a cidade de Vic - comunidade autônoma da Catalunha na Espanha - onde cresceu. A autora se formou em Filologia Árabe na Universidade de Barcelona e lançou seu primeiro livro, o ensaio Jo també sóc catalana, em 2004 e o primeiro romance L'últim patriarca, em $2008^{10}$, com o qual recebeu o Prêmio Ramon Llull de novela (2007) ${ }^{11}$. A obra de El Hachmi possui como foco temático o pertencimento, a identidade, discriminação racial, religião, liberdade sexual, representação da mulher e os imaginários criados em torno da migração, principalmente, em países ocidentais. Essas temáticas elevam o grau de importância da obra, visto que expõem o teor político-social de seu discurso. A autora parte do lugar de fala de uma mulher migrante, em uma região da Espanha atravessada por movimentos nacionalistas e separatistas onde a discriminação e o racismo contra árabes apresentam-se como um grande problema social.

O discurso construído pela autora em seus romances e ensaios e o próprio ato da escrita subverte o papel de subalternidade imaginado para uma mulher no contexto da migração. O subalterno, como salienta Gayatri C. Spivak (1995), destinado ao lugar do oprimido e silenciado pelas estruturas da opressão, é confrontado com o discurso de resistência de Najat El Hachmi, que questiona as culturas pelas quais transita (Catalunha/Espanha e Marrocos).

Atualmente, o discurso projetado por El Hachmi e suas obras continuam mostrando força e valor dentro e fora da comunidade literária. No dia 6 de janeiro, por exemplo, a escritora foi contemplada com mais um prêmio, Prêmio Nadal $2021^{12}$, pela originalidade do seu mais novo romance intitulado El lunes nos querrán $(2021)^{13}$ sobre liberdade e amizade.

A biografia de Najat El Hachmi e sua história de lutas colocam em evidência habilidades e características importantes para legitimar sua identidade social enquanto escritora e defensora dos direitos das mulheres e migrantes. Para além de sua projeção acadêmica como ensaísta e escritora reconhecida institucionalmente por seus pares, habilidade de saber-fazer, ela também é legitimada por sua posição de testemunha do vivido por seu histórico de migração. Outro ponto importante para a construção da identidade social da autora é seu engajamento social. El Hachmi não se resguarda à posição de sujeito apoiada apenas por seu prestígio institucional

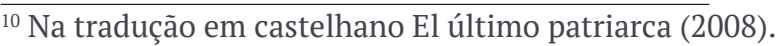

${ }^{11}$ Prêmio literário concedido anualmente a um romance escrito originalmente em catalão.

${ }^{12}$ O Prêmio Nadal de romances é uma das premiações mais antigas da Espanha e condecora desde 1945 romances inéditos em língua castelhana.

${ }^{13}$ Publicado em fevereiro de 2021.
} 
ou pelas experiências vividas enquanto migrante. Ela assume para si o papel de ativista, daquela que luta por uma causa e se propõe a falar publicamente de questões políticas e sociais as quais atravessam o tema da migração, das comunidades muçulmanas, do feminismo etc. Para tanto, a escritora contribui em vários veículos de comunicação, como o jornal El País ${ }^{1413}$ no qual escreve artigos e expõe seu posicionamento. Os qualitativos selecionados destacam o posicionamento da referida escritora e contribuem para dar fiabilidade ao discurso construído em seus romances, ensaios e artigos.

\section{Identidade discursiva: Os caminhos do transitar}

Após a reflexão sobre a constituição da identidade social de Najat El Hachmi, propor-se-á uma análise no que tange à identidade discursiva construída pela autora através da protagonista do romance La filla estrangera (2015). A identidade discursiva, segundo Charaudeau (2009), se constrói com base nos modos de tomada de palavra, na organização enunciativa do discurso e na manipulação dos imaginários sociodiscursivos alicerçados em duas estratégias: a de credibilidade intrinsecamente ligada à defesa de uma imagem de si no discurso e ancorada na construção de um projeto de fala que assegure a sinceridade do sujeito falante. E a estratégia de captação a qual tem por objetivo assegurar que o interlocutor da troca comunicativa, neste caso o leitor, perceba a intencionalidade do discurso construído, ou seja, que o leitor seja tocado pela narrativa. Nesse sentido, a construção identitária discursiva manifesta-se na seleção de palavras e na forma como o sujeito falante organiza o discurso em diálogo com os qualitativos da identidade social.

No romance analisado, a identidade discursiva está fundamentada como abordado anteriormente, na percepção de uma jovem marroquina sobre os desafios da migração. Seu discurso baseia-se na estratégia de captação pela dramatização de histórias e conflitos que perpassam sua vida, com o intuito de mobilizar valores afetivos e empáticos em seu interlocutor. O enredo se desenvolve em um dos momentos cruciais da vida dessa personagem, a fase entre os 18 e 19 anos. Nesse período, o que pode parecer natural para muitos jovens - a escolha de uma trajetória profissional - transforma-se em um grande dilema, já que, em sua cultura de origem, as mulheres deveriam dedicar-se ao casamento e aos cuidados da família. Tradicionalmente, as famílias muçulmanas se estruturam em torno de um núcleo familiar no qual a figura masculina está no centro. As mulheres, por sua vez, "encontram-se durante toda vida em um cenário de subordinação frente aos homens; se estão solteiras, devem obedecer às ordens do pai e, após o matrimônio, as de seus maridos.” (BUENO \& FERNÁNDEZ, 2016, p. 168 - tradução nossa).

${ }^{14}$ Disponível em <<: https://elpais.com/autor/najat-el-hachmi/ >> Acesso em: 24 de junho de 2021. 
A narrativa apoia-se, nesse contexto, no choque entre duas culturas (berbere ocidental) e entre dois espaços transitórios (Marrocos - Espanha), no qual um deles tem como representação a figura materna.

A mãe, ao contrário da jovem protagonista, foi criada dentro dos preceitos muçulmanos e, ao chegar à Espanha, já tinha uma visão estabelecida de um cotidiano e de uma cultura comum para muitas mulheres em seu entorno. Para ela, apesar do contexto adverso da migração, só haveria um destino para uma mulher: o da servidão e da obediência como é descrito no trecho do romance, quando a protagonista visita o Marrocos e reflete sobre o papel da mulher nessa sociedade:

Tengo la edad en que las chicas de aquí ya estarían casadas con hijos y
prepararían la comida y la cena, limpiarían, lavarían la ropa y cumplirían
con su rutina diaria de tareas de la casa sin delegarla en nadie más. Mi
madre siempre ha querido que estuviera preparada para eso, que me
preparase para ser ama de casa y, desde que era pequeña, me ha repetido
la misma frase: "Yo a tu edad...”. El objetivo de esa educación ha sido
siempre el mismo: que cuando me case, cuando esté en casa “de otros”, no
puedan tener nunca ni una sola queja de mí, que no puedan decir que no
soy lo bastante mujer, que soy una malcriada. (EL HACHMI, 2015, p. 43)

Na perspectiva da mãe, ser mulher relaciona-se ao cumprimento de certos ritos e deveres os quais não podem ser ressignificados, sob pena de colocar à prova sua própria dignidade dentro de sua comunidade. A figura da mãe, desse modo, é caracterizada por uma identidade discursiva cultural fortemente ligada à tradição e ao essencialismo que está em contato com um núcleo imutável e atemporal que liga o passado, o futuro e o presente numa linha ininterrupta que supõe fidelidade às origens (HALL, 2003, p.29). Essa fidelidade aparece na narrativa na busca constante da mãe por manter sua dignidade, legitimada pelo seguimento dos preceitos muçulmanos para a mulher e pelo olhar do outro, como na descrição feita pela personagem principal sobre sua mãe:

Su frente de mujer rifeña, su cara de digna amaciga de la cabeza a los pies, una señora con todas las letras. Admirable y admirada siempre, por dentro y por fuera. Su integridad es conocida por todas las mujeres de la ciudad; por todas las marroquíes, claro. (EL HACHMI, 2015, p. 19)

A imagem de boa muçulmana, que a personagem representada pela mãe almeja e tenta manter, não se encaixa à visão de mundo da protagonista do romance que se vê em um complexo conflito interno. Esse conflito reflete mais uma estratégia utilizada na construção da narrativa, o processo de polarização em que, de um lado, estaria o cumprimento dos preceitos culturais e religiosos da comunidade muçulmana e, do outro, a realização dos desejos individuais da protagonista. $\mathrm{O}$ sujeito falante, a partir desse processo, instiga o interlocutor a envolver-se no enredo e a fazer parte das reflexões e pensamentos da protagonista partilhados através da escrita. 
A escrita, como ato, possui um papel relevante no desenvolvimento da narrativa, visto que é a partir dela que a personagem principal pode revelar-se como sujeito despido de todos os olhares sobre sua conduta. Nesse espaço de autoconhecimento, o caderno que a acompanha durante sua trajetória serve como "palco" para a construção de uma identidade discursiva, muitas vezes, desdobrada, cindida e fragmentada. No início do romance, por exemplo, fica claro que a jovem protagonista está certa de que ela não se encaixa ao modelo de vida esperado para uma mulher na cultura muçulmana, e que a possibilidade de um casamento está fora de seus planos, mesmo que isso signifique ir contra os preceitos culturais de seu país de origem:

\begin{abstract}
Nunca le he dicho nada cuando suelta ese discursito, pero estos ya no son sus tiempos, ya no valgo solo para las tareas que sé hacer ni he pensado nunca en irme a vivir con mis suegros como han hecho nuestras madres y nuestras abuelas, mi vida será distinta. [...] De hecho, cuando mi madre hablaba de prepararme para el mañana, de qué dirán cuando tengas que cocinar y los libros no te sirvan de nada, yo siempre pensaba que esa no era ni sería nunca mi vida, que yo no me casaría ni tendría hijos ni haría de esposa, que no sería esposa de nadie y punto. (EL HACHMI, 2015, p. 43 - Grifos nossos).
\end{abstract}

Ela sente prazer em estudar, em desfrutar da liberdade de passear pelas ruas da cidade onde vive, sente vontade de descobrir o mundo. Em seus pensamentos, o desejo pela fuga e a recusa ao casamento sempre estiveram presentes como uma sombra que, apesar de ser apagada pela escuridão, sempre estará lá no menor resquício de luz.

A identidade projetada discursivamente pela personagem narradora está ligada à noção de identidade discursiva baseada no sujeito pós-moderno e, ao mesmo tempo, transnacional. Isso ocorre visto que, de maneira oposta à imagem unificada construída para a figura materna, a protagonista reivindica uma identidade fragmentada, múltipla e, por vezes, contraditória (HALL, 2015). Ela também rejeita "uma identidade formada apenas a partir dos critérios de raça ou de local de origem em proveito de uma identidade complexa, mutável, frequentemente multicultural e exterior ao recinto das lembranças” (PATERSON, 2015, p.182). Essa identidade discursiva fragmentada e multicultural é fortemente marcada na narrativa através da relação da protagonista com o rifenho ou amazigh (língua da relacionada à cultura marroquina) e a língua do pensamento (língua do país de acolhida) como mostra o excerto:

Con cada bucle de pensamientos, una idea me iba golpeando con mayor intensidad: si tuviera que explicar en esta lengua en la que pienso todo el proceso de hacer el pan, no sabría, me fallarían las palabras, porque, cuando lo hago, la descripción se me llena de palabras de la lengua de mi madre que nadie más puede entender. Solo alguien que fuese como yo, alguien que también tuviera una madre como la mía y hubiese aprendido esta lengua que nos es extranjera y la hubiera interiorizado, como yo, 
hasta el punto de que se hubiera convertido en la lengua principal de sus pensamientos, solo con alguien así podría hablar como yo me hablo a veces, mezclando las dos lenguas. (EL HACHMI, 2015, p. 26)

A personagem, ao relatar sua relação com as línguas, expõe as fronteiras que envolvem o bilinguismo quando não há paridade de prestígio entre elas. A língua da mãe é colocada em segundo plano, posto que, com ela, não é possível se comunicar com ninguém além dos limites da cultura muçulmana. $\mathrm{O}$ catalão, por sua vez, toma o lugar principal em sua vida (trabalho e estudos) e em seus pensamentos. Porém, ao observar o relato da jovem, pode-se afirmar que não é possível ignorar uma língua em detrimento da outra. Para acessar o universo da cultura marroquina, os ensinamentos da mãe, os preparos culinários, a jovem precisa retornar ao riquenho/amazigh. Nesse contexto, soma-se à cisão entre culturas distintas o questionamento sobre seu lugar de pertencimento. Afinal, a que mundo a protagonista pertence? Existe de fato um lugar de pertencimento?

A difícil tarefa de encontrar um lugar que acolha a protagonista revela-se também pela crítica ao tratamento dado aos migrantes de origem marroquina na Espanha. Apesar de a jovem ter um bom conhecimento da língua catalã e um ótimo rendimento escolar, ainda assim, ela não consegue ser totalmente integrada ao cenário europeu. O imaginário sociodiscursivo negativo e subalterno, criado em torno do sujeito de origem oriental, o racismo e falta de oportunidades, coloca em evidência a dificuldade da integração em uma sociedade que se mostra pouco disposta a respeitar diferenças:

\begin{abstract}
Aunque, bien pensado, en esta ciudad es poco probable que una marroquí pase desapercibida, porque su sola presencia, con la cabeza cubierta y los ropajes largos, ya llama la atención de quienes han vivido aquí toda la vida y no entienden esta repentina presencia de forasteros. (EL HACHMI, 2015, p. 140)
\end{abstract}

E, mesmo quando não existe a marcação de origem, como traços na vestimenta ou o uso do véu, o imaginário social está marcado por qualquer outro vestígio que denote sua condição quase permanente de estrangeiro/migrante que está fora. Como relatado nas entrelinhas do enredo, quando a protagonista vai a uma agência de emprego à procura de uma vaga:

Me aliso el pelo con una mano y, finalmente, entro. Le digo a la chica que vengo a apuntarme. Me pide que me siente, me toma los datos, se queda mirando mi permiso de residencia. Hoy me ha entrado una oferta que te puede interesar, de limpieza y cocina. Está acerca de aquí. (EL HACHMI, 2015, p. 68 - Grifos nossos)

Por meio do jogo de palavras "permiso de residencia" e "limpieza y cocina", é possível compreender a intencionalidade do sujeito falante em marcar a visão 
estereotipada construída para o migrante. Este estaria destinado, quase que diretamente, a atividades relacionadas à prestação de serviços, infelizmente, pouco prestigiada socialmente na cultura ocidental. $\mathrm{O}$ ato da funcionária da agência de emprego destaca, ainda, a sobreposição da identidade migrante em detrimento das qualificações apresentadas pela personagem narradora que se vê mais uma vez frustrada com a impossibilidade de ser reconhecida em sua individualidade.

A sensação de permanecer sempre como forasteira no país onde cresceu e a pressão da mãe pela aceitação dos preceitos da cultura muçulmana fazem a protagonista abdicar de seus desejos e aceitar o destino que lhe foi planejado: o casamento, o uso do véu e, consequentemente, a gravidez. Um silenciamento total de si em prol da satisfação do outro que a leva à beira da loucura e ao adoecimento:

Hoy tenía fiesta; después de muchos días seguidos trabajando un día sí y el otro día también, del Ayuntamiento al seminario, hoy podía descansar, y pensaba levantarme por la mañana y darme un baño largo, quizá incluso ir a la peluquería. Desde que llevo pañuelo tengo más ganas que nunca de ir a la peluquería. Pero he ido hasta el comedor, todavía con el camisón puesto, allí me he desplomado en el suelo. Sin perder la conciencia, pero incapaz de tenerme en pie, como si los músculos y los huesos no pudieran sostenerme. Entonces he empezado a gritar como una niña, no, mejor dicho, como un animal atado por las cuatro patas [...] (EL HACHMI, 2015, p. 210-2011)

A opressão sofrida pela jovem manifesta-se por todo seu corpo como uma força incontrolável que A leva a aproximar-se da figura de um animal no cativeiro, o qual luta por sua liberdade. A imagem de fragmentação, sustentada no decorrer da narrativa, dá lugar à construção de uma identidade discursiva que passa da submissão à resistência. A protagonista deixa tudo o que a violentou para trás e rompe com todos os laços de submissão através da fuga.

\section{Considerações finais}

O discurso construído por Najat El Hachmi no romance La filla estrangera (2015) questiona as formas de subordinação da mulher em sua condição de migrante na contemporaneidade. Suas estratégias discursivas de construção identitária colocam em evidência a necessidade de se romper com imagens estanques e estereotipadas em relação ao migrante e, principalmente, à mulher migrante/ muçulmana. Assim, como salienta Stuart Hall (2003) em seus estudos sobre a construção de identidades diaspóricas, não é possível basear as representações de migrantes sem observarmos seus contextos de chegada, a cultura de onde vieram e todas as características interseccionais que compõem o sujeito. Nesse contexto, o desenvolvimento de um enredo, que parte da posição íntima de uma jovem atravessada por questões religiosas, culturais e de pertencimento, em um ambiente de grande opressão, eleva a relevância política e literária do romance 
por tirar do silenciamento a voz de sujeitos condenados à subalternidade. El Hachmi reivindica, assim, a possibilidade de se inscrever no mundo não apenas como sujeito migrante, mas como um sujeito em trânsito, multifacetado e diverso.

\title{
NAJAT EL HACHMI - DISCOURSE OF RESISTANCE AND IDENTITY IN THE CONTEXT OF MIGRATION
}

\begin{abstract}
The following paper aims to analyze the novel La filla estrangera (2015), written by Najat El Hachmi, in order to verify the identity construction using the migration narrative of women in migration contexts. Furthermore, the study emphasizes the discourse of resistance, present in El Hachmi's work, and the claim for a identity construction focusing her own voice and her own existence as an autonomous subject. As theoretical base of this discussion, this paper relies on a discourse analysis's perspective (Charaudeau 2009), with a focus on social and discursive identity. The analysis reveals the work of El Hachmi as an important manifestation of resistance. Questioning the imaginaries of women in migration contexts, the author puts on the map how urgent it is to analyze and to discuss identity constructions in migration contexts in a more plural perspective, taking the voice of people in migration into account.
\end{abstract}

Keywords: Najat El Hachmi; Migration; Discourse Analysis; Feminist writing; Identity.

\section{Referências}

ALVES, Luciane \& NEUMANN, Gerson. A escrita entre mundos de Najat El Hachmi: gênero, política e pertencimento. Revista Conexão Letras, Vol.13. Porto Alegre 2018, p. 65-76.

BEAUVOIR, Simone de. O segundo sexo. 1. Fatos e mitos. 4. ed. Tradução de Sérgio Millet. São Paulo: Difusão Europeia do Livro, 1970.

BUENO, Andrés Montaner \& FERNÁDEZ, Eduardo Encabo. Reflexiones sobre la construcción de la identidad cultural a partir del estudio de la novela La hija extranjera de Najat el Hachmi: implicaciones sociales y educativas. In: Europa: identidad, migración y exilio. Espéculo no 56 UCM - 2016. p. 159-174

CANALES, Miriam Abselam. La identidad compleja de Najat El Hachmi Buhhu. In: Ambigua, Revista de Investigaciones sobre Género y Estudios Culturales. Sevilla: n.3, 2016. p. 23-38.

CHARAUDEAU, P. Les stéréotypes, ć est bien, les imaginaires, ć est mieux. In: BOYER, H. Stéréotypage, stéréotypes: fonctionnements ordinaires et mises en scène. Langue(s), discours. Vol. 4. Paris: Harmattan, 2007. p. 49-63. Disponível em: <<https://www.upo.es/revistas/index.php/ambigua/article/view/1971 >> Acesso em: 24 de junho de 2021 
CHARAUDEAU, Patrick. Identidade social e identidade discursiva, o fundamento da competência comunicacional In: PIETROLUONGO, Márcia (Org.). O trabalho da tradução. Rio de Janeiro: Contracapa, 2009, p. 309-326. Disponível em: <http://www.patrick-charaudeau.com/Identidade-social-eidentidade.html>. Acesso em: 24 junho 2021.

HOOKS, bell. Talking Back: Thinking Feminist, Talking Black. Boston: South End Press, 1989.

EL HACHMI, Najat. Jo també soc catalana. Barcelona: Columna, 2004.

EL HACHMI, Najat. La hija extranjera. Tradução: Rosa María Prats. Barcelona: Planeta, 2015.

HALL, Stuart. Da diáspora. Identidades e mediações culturais. Belo Horizonte: UFMG/UNESCO, 2003.

HALL, Stuart. A identidade cultural na pós-modernidade. 9e.d. Rio de Janeiro: DP\&A, 2004.

MARINUCCI, Roberto \& MILESI, Rosita. Mulheres migrantes e refugiadas a serviço do desenvolvimento humano dos outros. Disponível em: https://www. migrante.org.br/migracoes/artigo-mulheres-migrantes-e-refugiadas-a-servicodo-desenvolvimento-humano-dos-outros/. Acesso em: 24 de junho de 2021.

PATERSON, J. M. (2015). O sujeito em movimento: pós-moderno, migrante e transnacional. Letras De Hoje, 50(2), 179-184. Disponível em: https://doi. org/10.15448/1984-7726.2015.2.21339 Acesso em: 24 de junho de 2021.

SPIVAK, G. C. Pode o subalterno falar?. Belo Horizonte: Editora UFMG, 2010.

Recebido em 12 de março de 2021

Aprovado em 28 de maio de 2021 